\title{
Diferença da susceptibilidade de Actinomyces viscosus a cefalotina in vitro e in vivo em um cão com artrite séptica: relato de caso
}

\author{
[Difference of the susceptibility of Actinomyces viscosus to cephalothin in vitro and in vivo in a dog \\ with septic arthritis - Case report]
}

\section{"Relato de Caso/Case Report"}

\author{
Silvana Marques Caramalac ${ }^{1}$, Simone Marques Caramalac ${ }^{1}$, Gustavo Gomes de Oliveira ${ }^{1}$, \\ Mariana Isa Poci Palumbo ${ }^{2}$, Veronica Jorge Babo-Terra ${ }^{2 *}$
}

\author{
${ }^{1}$ Programa de Pós-Graduação em Ciências Veterinárias, Faculdade de Medicina Veterinária e Zootecnia (FAMEZ), \\ Universidade Federal de Mato Grosso do Sul, Campo Grande-MS, Brasil. \\ ${ }^{2}$ Faculdade de Medicina Veterinária e Zootecnia (FAMEZ), Universidade Federal de Mato Grosso do Sul, Campo \\ Grande-MS, Brasil. \\ *Autor para correspondência/Corresponding author: E-mail: vjb@terra.com.br
}

\begin{abstract}
Resumo
A artrite séptica consiste na inflamação da estrutura articular secundária a contaminação bacteriana. O presente estudo tem como objetivo relatar o tratamento bem-sucedido de artrite séptica em um cão macho, de dois meses de idade, da raça boxer, com claudicação de membro torácico esquerdo, apesar da resistência demonstrada no antibiograma. Realizou-se coleta do líquido sinovial para cultura e antibiograma e foi iniciada antibioticoterapia empírica com cefalotina até obtenção dos resultados. O agente isolado foi Actinomyces viscosus, sendo resistente à amoxicilina, amoxicilina + ácido clavulânico, azitromicina, cefalexina, cefalotina, doxiciclina, sulfazotrim e tetracilina. Entretanto, pelo fato de, no momento da obtenção deste resultado, o cão já ter apresentado melhora clínica significativa, optou-se pela manutenção do tratamento inicial. O conhecimento acerca da farmacocinética, associado ao resultado do antibiograma e a experiência da aplicação clínica dos antibióticos são importantes ferramentas para estabelecimento da terapia mais apropriada. Acreditase que a diferença de suscetibilidade da bactéria à cefalotina in vitro e in vivo possa ser atribuída à distribuição deste fármaco, que sabidamente apresenta maiores concentrações nos tecidos osteoarticulares.
\end{abstract}

Palavras-chave: antibiograma; articulação; cefalosporina; claudicação; resistência.

\begin{abstract}
Septic arthritis consists of inflammation of the joint structure secondary to bacterial contamination. The present study aims to report the successful treatment of septic arthritis in a 2-month-old male Boxer dog, with lameness of the left thoracic limb despite the resistance demonstrated in the antibiogram. Synovial fluid was collected for culture and antibiogram, and empiric antibiotic therapy with cephalothin was started until the results were obtained. The agent isolated was Actinomyces viscosus, resistant to amoxicillin, amoxicillin + clavulanic acid, azithromycin, cephalexin, cephalothin, doxycycline, sulfazotrim, and tetracycline. However, due to the fact that, at the time of obtaining this result, the dog had already presented significant improvement, we opted for continuing the initial treatment. Knowledge about pharmacokinetics associated with the antibiogram result and the clinical experience of antibiotics are important tools for establishing the most appropriate therapy. We believe that the difference in susceptibility of the bacterium to cephalothin in vitro and in vivo can be attributed to the distribution of this drug, which is known to have higher concentrations in osteoarticular tissues.
\end{abstract}

Keywords: antibiotic; joint; cephalosporin; lameness; resistance. 


\section{Introdução}

O aumento do volume de uma ou mais articulações pode estar relacionado a diversos diagnósticos diferenciais, sendo o mais grave deles a artrite séptica (Mathews et al., 2008). Esta é uma artropatia inflamatória com contaminação bacteriana, levando a sinais clínicos de dor, inchaço e claudicação (Mulon et al., 2016), podendo afetar diferentes espécies, como humanos, equinos e caninos (Dokuzeylül et al., 2014). Considerada uma emergência, a artrite séptica pode resultar desde a perda funcional da articulação até a morte (Mathews et al., 2008; Ross et al., 2017). As principais espécies bacterianas isoladas nesta artropatia inflamatória são Staphylococcus intermedius, $S$. aureus, $S . \quad \beta$-haemolytic e Streptococcus spp., podendo estas atingir as articulações por três vias distintas: penetração direta (cirúrgica ou traumática), propagação de infecção localizada nos tecidos moles adjacentes ou pela via hematógena (Clements et al., 2005), sendo raramente complicações de artroscopias ou injeções terapêuticas locais (Ross, 2017).

O dano à articulação resulta da invasão do micro-organismo, inflamação local e isquemia tecidual, havendo ação direta das enzimas e toxinas bacterianas sobre a cartilagem (Mulon et al., 2016). Associado a isso, os neutrófilos locais liberam substâncias oxidativas e proteínas lisossomais, que pioram ainda mais o dano tecidual (Visai et al., 2014; Ross, 2017). Por se tratar de um tecido pouco vascularizado, o aumento da pressão intra-articular acarreta a isquemia na cartilagem, contribuindo ainda mais à destruição da matriz local (Mulon et al., 2016).

O tratamento consiste no combate à infecção e reestabelecimento da função articular (Scharf et al., 2015). O presente estudo tem como objetivo relatar um caso de artrite séptica por Actinomyces viscosus em um cão com claudicação de membro torácico esquerdo, e o sucesso terapêutico apesar da resistência demonstrada no antibiograma.

\section{Descrição do Caso}

Foi atendido no Hospital Veterinário da Universidade Federal de Mato Grosso do Sul um cão da raça boxer, macho, com dois meses de idade, pesando 4,250 quilos cuja queixa principal apresentada pelo tutor foi claudicação em membro torácico esquerdo. Pela anamnese, constatou-se que animal já vinha recebendo tratamento parenteral em clínica particular, para gastroenterite viral. No exame físico, o paciente demonstrou apatia, claudicação e elevado grau de desconforto durante a palpação das articulações escápuloumeral e úmero-rádio-ulnar, que estavam aumentadas de volume e de consistência flutuante. A temperatura retal foi $38,6 \mathrm{C}^{\text {o }}$. Não foram detectadas alterações ósseas ao exame ortopédico e radiográfico. Exame hematológico revelou leucocitose $\left(52.800 / \mathrm{mm}^{3}\right.$, referência 6.000 a $\left.17.000 / \mathrm{mm}^{3}\right)$ por neutrofilia $\left(47.520 / \mathrm{mm}^{3}\right.$, referência 3.000 a $11.500 / \mathrm{mm}^{3}$ ). Amostras do líquido sinovial foram aspiradas assepticamente das articulações acometidas para análise, sendo observado predomínio de neutrófilos degenerados e presença de bactérias intracitoplasmáticas, sugestivo de processo inflamatório purulento séptico. O líquido sinovial foi enviado para cultura e antibiograma, e iniciado o tratamento com cefalotina (30 mg/kg, IV, TID), meloxicam $(0,1$ $\mathrm{mg} / \mathrm{kg}, \mathrm{VO}, \mathrm{SID}$ ) e dipirona ( $25 \mathrm{mg} / \mathrm{kg}, \mathrm{VO}, \mathrm{BID})$ até obtenção dos resultados.

Cinco dias após o início do tratamento o tutor relatou melhora significativa dos sinais clínicos, com diminuição da claudicação e da dor à palpação. $\mathrm{Na}$ cultura bacteriana houve o crescimento de Actinomyces viscosus, a qual apresentou resistência e sensibilidade aos antibióticos listados na Tabela 1.

Tabela 1. Susceptibilidade antibiótica de Actinomyces viscosus obtido a partir de amostra de líquido sinovial de um cão macho de 2 meses de idade da raça boxer com artrite séptica.

\begin{tabular}{|c|c|}
\hline Sensível & Resistente \\
\hline \multirow[b]{2}{*}{ Ciprofloxacina } & Amoxicilina \\
\hline & $\begin{array}{c}\text { Amoxicilina + ácido } \\
\text { clavulânico }\end{array}$ \\
\hline \multirow{2}{*}{ Enrofloxacina } & Azitromicina \\
\hline & Cefalexina \\
\hline \multirow{2}{*}{ Gentamicina } & Cefalotina \\
\hline & Doxiciclina \\
\hline \multirow{2}{*}{ Norfloxacina } & Sulfazotrim \\
\hline & Tetraciclina \\
\hline
\end{tabular}

Devido à melhora clínica observada e ao fato de que os antibióticos a que a bactéria era suscetível poderem causar comprometimento da linha epifisária, optou-se pela continuidade do tratamento com cefalosporina, por via oral (cefalexina $30 \mathrm{mg} / \mathrm{kg}$ TID). Para avaliação da eficácia da terapia, foram realizados hemograma e acompanhamento do quadro clínico, sendo verificado diminuição significativa da leucocitose $\left(19.500 / \mathrm{mm}^{2}\right)$, com resolução completa do caso após 14 dias, com ausência do comprometimento 
da função articular a partir da avaliação física do paciente.

\section{Discussão}

A artrite séptica pode causar danos permanentes a articulação, devido à dificuldade da resolução completa do caso e ao elevado grau de sensibilidade das estruturas ali localizadas (Mathews et al., 2008). Os sinais clínicos apresentados pelo paciente consistiram em aumento do volume e da temperatura articular, além de dor local e claudicação, como descrito por Mathews et al. (2008). Isso ocorre devido a reação inflamatória local, em que há o incremento da circulação sanguínea e migração de leucócitos para dentro da articulação, além da infiltração de fibrina no espaço articular (Mulon et al., 2016). As enzimas proteolíticas dos leucócitos e células sinoviais dissolvem os proteoglicanos da cartilagem articular (Ross, 2017). Essas lesões, quando cicatrizam, causam muitas vezes rigidez articular e anquilose (Mathews et al., 2008; Ross, 2017).

As consequências desta afecção dependem não apenas da quantidade, tipo de agentes etiológicos envolvidos ou estado geral do paciente, mas também da velocidade e escolhas realizadas para o tratamento. No presente relato optou-se por iniciar antibioticoterapia empírica até obtenção do resultado da cultura e antibiograma, sendo optado pela classe de antibiótico que alcança maior concentração no sistema osteoarticular. Estudos revelaram que o tratamento imediato foi essencial para evitar danos permanentes (Mathews et al., 2008; Mulon et al., 2016). O tratamento inicial da artrite séptica é relativamente simples, mas a efetividade no restabelecimento da mobilidade normal do membro é baixa (Dokuzeylül et al., 2014). O fato de o animal ter tido resposta favorável no início do tratamento foi fundamental para sua evolução e para um bom prognóstico.

Clementes et al. (2005), em estudo realizado com 31 cães acometidos com artrite séptica, verificaram que o tratamento médico e/ou cirúrgico foi geralmente bem-sucedidos para resolução das infecções, entretanto, foram frequentemente frustrantes quanto ao restabelecimento da função normal da articulação, sendo o tratamento ideal ainda alvo de discussões (Mathews et al., 2008). Por se tratar de um animal em fase de crescimento, a resolução completa do presente caso se torna ainda mais relevante, uma vez que limitação ao movimento articular resulta em deformidades anatômicas importantes, que podem evoluir para sobrecarga das demais articulações e assim, comprometimento da locomoção e da saúde do esqueleto apendicular. Assim, a rapidez no diagnóstico e instituição do tratamento foram imprescindíveis para que a funcionalidade completa da articulação fosse preservada, não sendo observada qualquer limitação ao movimento após a alta do paciente.

Um estudo retrospectivo realizado por Scharf et al. (2015) concluiu que cultura de fluído sinovial de cães com suspeita de artrite séptica tem acurácia baixa, necessitando de desenvolvimento em um meio mais eficiente de identificação de bactérias em animais com suspeita desta afecção. Entretanto, no presente relato, a cultura bacteriana foi eficiente tanto para identificação do agente A. viscosus, como para a realização do antibiograma.

O gênero Actinomyces compreende um grupo de bactérias aeróbicas ou microareróbicas gram-positivas filamentosas, catalase-positivas encontradas sobretudo em cavidade oral de humanos e animais (Davenport et al., 1975). Esta bactéria comensal passa a se tornar patogênica na presença de um ambiente suscetível para sua replicação, muitas vezes causada por lesão perfurante ou ferida (Koenhemsi et al., 2014). A maioria dos casos desta afecção são causadas por bactérias gram-positivas, o que é explicado pela superioridade desses organismos em ligar-se aos tecidos conectivos e matriz proteica extracelular (Ross, 2017), apesar de a espécie isolada no presente relato não ser frequente causadora de artrite séptica.

Apesar dos avanços no desenvolvimento de meios de cultura, o diagnóstico da artrite séptica continua sendo um desafio para os clínicos, uma vez que o quadro geral do paciente pode ou não ser acompanhada de febre, leucocitose ou crescimento bacteriano em cultura (Mathews et al., 2008). No material coletado do animal deste relato houve crescimento em meio de cultura e observação de bactérias na citologia sinovial, sendo estas ferramentas consideradas padrão-ouro para o diagnóstico definitivo da artrite séptica. Segundo Clementes (2005), a sensibilidade da citologia do líquido sinovial e a cultura bacteriana para diagnóstico de artrite séptica apresentam sensibilidade variada entre os estudos. Os principais diferenciais para dor articular com claudicação progressiva incluem fraturas, reação periosteal, panosteíte, reação vacinal, artrite 
séptica, osteodistrofia fibrosa e celulite juvenil (Wentzell, 2011).

O sucesso da antibioticoterapia está mais relacionado aos fatores relativos à distribuição do fármaco no hospedeiro do que efetivamente aos resultados do teste in vitro (Devriese e Dutta, 1981). Segundo estes mesmos autores, dificilmente uma bactéria que demonstra resistência a determinado antibiótico no antibiograma terá boa resposta no organismo vivo, exceto nas situações em que a medicação é aplicada diretamente no local ou quando a área afetada apresenta elevada concentração do fármaco. Os antibióticos do grupo da cefalosporina são altamente indicados para tratamento de afecções supurativas osteoarticulares, uma vez que apresentam elevada concentração nestes tecidos. Isso pode justificar a razão pela qual a cefalosporina utilizada no presente relato mostrou-se eficiente no tratamento apesar de sua resistência no teste laboratorial.

O tratamento deve ser iniciado rapidamente com doses elevadas de antibióticos por via intravenosa, podendo a via de administração ser trocada para oral após 2-5 dias, como realizado no presente relato. A terapia empírica deve cobrir sempre Staphylococcus aureus e patógenos respiratórios comuns (Pääkkönen e Peltola, 2013). O não crescimento bacteriano do material coletado não significa necessariamente ausência de infecção: isso pode ocorrer devido a início de antibioticoterapia anterior a coleta, baixa bacteremia, pequena quantidade de material coletado ou necessidade de meios de cultura mais específicos (Ross, 2017).

Ocasionalmente, a artrite séptica pode resultar de trauma penetrante direto, como mordidas ou injeções (Ross, 2017). No presente caso, a perda da integridade dermatológica, internação prévia (com cateterização e injeções múltiplas) e imunossupressão foram condições decisivas para instalação do quadro clínico, sendo esses fatores considerados "de risco" para o desenvolvimento de artrite séptica (Mathews et al., 2008; Ross, 2017). Assim, evidencia-se a importância da anamnese, cujo histórico de hospitalização direcionou ao diagnóstico mais preciso (Mathews et al., 2008). Além disso, ressalta-se a importância da assepsia adequada na realização de procedimentos rotineiros, além da manutenção da limpeza tanto do ambiente como dos pacientes hospitalizados, na prevenção do desenvolvimento de infecções secundárias.

\section{Conclusão}

A susceptibilidade da bactéria ao antibiótico pode apresentar variação nos testes realizados in vitro $\mathrm{e}$ in vivo. $\mathrm{O}$ clínico deve conhecer a farmacocinética, espectro de ação e os potenciais efeitos colaterais dos antibióticos que serão utilizados, a fim de se determinar qual a escolha mais apropriada em cada caso. A instituição rápida do tratamento adequado foi imprescindível para que o desfecho do caso fosse favorável. Evidenciase também a relevância do histórico para o diagnóstico final, além da importância da realização de procedimentos de assepsia adequada na aplicação de medicamentos, venopunção ou cateterização na prevenção de infecções secundárias.

\section{Conflito de Interesse}

Os autores declaram que não há conflito de interesse.

\section{Agradecimentos}

À Coordenação de Aperfeiçoamento de Pessoal de Nível Superior (CAPES) pelo auxílio financeiro para desenvolvimento deste artigo.

\section{Referências}

Clements, D.N.; Owen, M.R.; Mosley, J.R.; Carmichael, S.; Taylor, D.J.; Bennett, D. Retrospective study of bacterial infective arthritis in 31 dogs. Journal of Small Animal Practice, 46(4):171-176, 2005.

Davenport, A.A.; Carter, G.R.; Patterson, M.J. Identification of Actinomyces viscosus from canine infections. Journal of Clinical Microbiology, 1(1):75-78, 1975.

Devriese, L.A.; Dutta, G.N. Antibiotic sensitivity testing: correlations between in vitro tests and in vivo situations. Annales de Recherches Vétérinaires, 12(1):41-46, 1981.

Dokuzeylül, B.; Metiner, K.; Kahraman, B.B., Kayar, A.; Özgür, N.Y. Early detection of septic arthritis caused by Streptococcus dysgalactiae subspecies equisimilis in a dog-a case report. Acta Veterinaria Brno, 83(3):261-264, 2014.

Koenhemsi, L.; Sigirci, B.D.; Bayrakal, A.; Metiner, K.; Gonul, R.; Ozgur, N.Y. Actinomyces viscosus isolation from the skin of a cat. Israel Journal of Veterinary Medicine, 69(4):239-242, 2014.

Mathews, C.J.; Kingsley, G.; Field, M.; Jones, A.; Weston, V.C.; Phillips, M.; Walker, D.; Coakley, G. Management of septic arthritis: a 
systematic review. Postgraduate Medical Journal, 84(991): 265-270, 2008.

Mulon, P.; Desrochers, A.; Francoz, D. Surgical management of septic arthritis. Veterinary Clinics: Food Animal Practice, 32(3):777795, 2016.

Pääkkönen, M.; Peltola, H. Treatment of acute septic arthritis. The Pediatric Infectious Disease Journal, 32(6):684-685, 2013.

Ross, J.J. Septic arthritis of native joints. Infectious Disease Clinics, 31(2):203-218, 2017.

Scharf, V.F.; Lewis, S.T.; Wellehan, J.F.; Wamsley, H.L.; Richardson, R.; Sundstrom, D.A.; Lewis, D.D. Retrospective evaluation of the efficacy of isolating bacteria from synovial fluid in dogs with suspected septic arthritis. Australian Veterinary Journal, 93(6): 200203, 2015.

Visai, L.; Ferrari, D.; Barbu, E.M.; Liang, X.; Ganesh, V.K.; Höök, M.; Imbriani, M. Staphylococcal biofilm formation and development: Related diseases, host immune responses and therapy. Prokaryotes: physiology, biochemistry and cell behavior. Cidade: Nova Science Publishers, 2014. 282p.

Wentzell, M.L. Hypertrophic osteodystrophy preceding canine juvenile cellulitis in an Australian shepherd puppy. The Canadian Veterinary Journal, 52(4):431, 2011. 